\title{
Universal Filter Using Single Commercially Available IC: LT1228
}

\author{
Surapong Siripongdee and Winai Jaikla \\ Department of Engineering Education, Faculty of Industrial Education, King Mongkut's Institute of Technology Ladkrabang, Thailand
}

\begin{abstract}
In electrical and electronic engineering, the filter is very importance circuit. A voltage-mode three inputs single output second-order multifunction filter is presented in this paper. The proposed filter is based on RLC parallel circuit. The main active element is the commercially available IC from Linear Technology Inc, LT1228. The filter consists of single LT1228, single resistor and two capacitors. Five output second-order filter responses, namely bandpass (BP), band-stop (BS), high-pass (HP), low-pass (LP) and all-pass (AP) functions are achieved. Each output response can be selected without component matching condition and the requirement of double gain amplifier. The quality factor and natural frequency can be electronically controlled. PSpice simulation results suing macro model of LT1228 are in close agreement with the theory.
\end{abstract}

\section{Introduction}

In electrical and electronic engineering, the biquadratic or second order filter has been important building blocks [1]. Also, this filter is the basic block to design high order filter. Especially, the second order multifunction filter which provides many filter responses in the same circuit has been gained significant attention and has become an interesting research topic. The multiple-inputs singleoutput (MISO) universal filter is the interesting one and has been continuously proposed. In case of voltage mode MISO, the selection of output voltage by switching on or off the input voltages should be done without the matching condition of passive and active elements. Moreover, the additional double gain amplifier should not be required.

In literature, there are a lot of MISO universal filters [2]-[15]. Unfortunately, these MISO universal filters have some drawbacks for example, need of matching condition, requirement of additional double gain amplifier, electronic uncontrollability, requirement of many active and passive element. The active elements used in some previous MISO universal filter are not commercially available.

The contribution of this paper is to propose a second order voltage-mode MISO multifunction filter using commercially available IC, LT1228 [16] as the active element. The LP, HP, BP, BS and AP responses are achieved without changing circuit topology. The matching condition of the passive and active element is not required. Also the additional double gain voltage amplifier doesn't need. The quality factor and natural frequency can be electronically tuned. It consists of single LT1228, single resistor and two capacitors. Through PSpice simulation using commercially available
IC also demonstrates improvements in terms of performance.

\section{Circuit configuration and analysis of the proposed filter}

\subsection{LT1228}

Operational transconductance amplifier (OTA) has attracted considerable attention to design high performance electronics circuits. OTA is basically current mode devices and is used in high frequency applications. Mostly, its transconductance gain $\left(\mathrm{g}_{\mathrm{m}}\right)$ can be electronically controlled which allows the OTA based circuits are controlled by microcontroller or microcomputer. Many commercial OTA ICs are available for example CA3080 from Intersil, LM13700 from National Semiconductor, MAX543 from MAXIM. The LT1228 from Linear Technology Inc is the interesting one. It is the combination of OTA and current feedback amplifier. The port name, electrical symbol and equivalent of LT1228 are illustrated in Fig. 1. The electrical characteristic is shown in Eq. (1).

$$
\left(\begin{array}{l}
I_{v+} \\
I_{v-} \\
I_{y} \\
V_{x} \\
V_{w}
\end{array}\right)=\left(\begin{array}{cccc}
0 & 0 & 0 & 0 \\
0 & 0 & 0 & 0 \\
g_{m} & -g_{m} & 0 & 0 \\
0 & 0 & 1 & 0 \\
0 & 0 & 0 & R_{T}
\end{array}\right)\left(\begin{array}{l}
V_{+} \\
V_{-} \\
V_{y} \\
I_{x}
\end{array}\right)
$$

where $\mathrm{R}_{\mathrm{T}}$ is the transresistance gain. In an ideal case, $\mathrm{R}_{\mathrm{T}}$ is typically very large and can be considered as infinite value. The $\mathrm{g}_{\mathrm{m}}$ of LT1228 is controlled by DC bias current $\mathrm{I}_{\mathrm{B}}$ as follows 


$$
g_{m}=10 I_{B}
$$

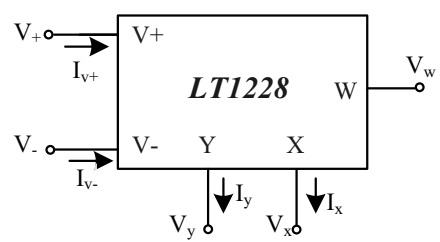

(a)

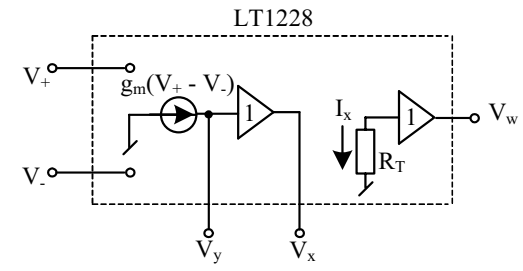

(b)

Figure 1. (a) Electrical symbol of LT1228 (b) its equivalent circuit.

\subsection{Proposed three input single output voltage mode universal filter}

The proposed filter is developed from passive RLC parallel circuit which consists of three input voltages, $V_{\text {in } 1}$, $\mathrm{V}_{\text {in2 }}$ and $\mathrm{V}_{\text {in } 3}$ and single output voltage $\mathrm{V}_{\mathrm{o}}$. The filter constructed from single LT1228, single resistor and two capacitors as shown in Fig. 2. Based on RLC parallel circuit, the output voltage of the filter is obtained as

$$
V_{O}=\frac{s^{2} V_{i n 2}+s \frac{V_{i n 3}}{C_{2} R}+\frac{g_{m} V_{i n 1}}{C_{1} C_{2} R}}{s^{2}+\frac{s}{C_{2} R}+\frac{g_{m}}{C_{1} C_{2} R}}
$$

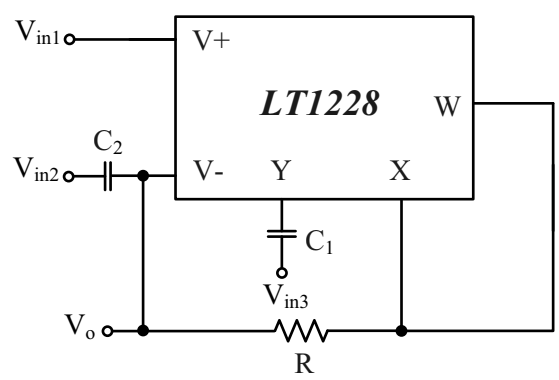

Figure 2. Three inputs single output voltage mode filter using single commercially available IC, LT1228.

From Eq. (3), a specific output filter responses can be selected by applying input voltage to node $\mathrm{V}_{\mathrm{in} 1}, \mathrm{~V}_{\mathrm{in} 2}$ and $\mathrm{V}_{\text {in } 3}$ with following:

To obtain the band-pass (BP) function, the input voltage is applied at node $V_{\text {in3 }}$ while node $V_{\text {in1 }}$ and $V_{\text {in2 }}$ are grounded, then the voltage transfer function is obtained as

$$
\frac{V_{O}}{V_{\text {in }}}=\frac{s \frac{1}{C_{2} R}}{s^{2}+\frac{s}{C_{2} R}+\frac{g_{m}}{C_{1} C_{2} R}}
$$

To obtain the band-stop (BS) function, the input voltage is applied at node $V_{\text {in1 }}$ and $V_{\text {in2 }}$, while node $V_{\text {in } 3}$ is connected to ground, then the voltage transfer function is obtained as

$$
\frac{V_{O}}{V_{\text {in }}}=\frac{s^{2}+\frac{g_{m}}{C_{1} C_{2} R}}{s^{2}+\frac{s}{C_{2} R}+\frac{g_{m}}{C_{1} C_{2} R}}
$$

To obtain the high-pass (HP) function, the input voltage is applied at node $V_{\text {in2 }}$, while node $V_{\text {in1 } 1}$ and $V_{\text {in3 }}$ are connected to ground, then the voltage transfer function is obtained as

$$
\frac{V_{O}}{V_{i n}}=\frac{s^{2}}{s^{2}+\frac{s}{C_{2} R}+\frac{g_{m}}{C_{1} C_{2} R}}
$$

To obtain the low-pass (LP) function, the input voltage is applied at node $V_{\text {in } 1}$, while node $V_{\text {in2 }}$ and $V_{\text {in3 }}$ are connected to ground, then the voltage transfer function is obtained as

$$
\frac{V_{O}}{V_{\text {in }}}=\frac{\frac{g_{m}}{C_{1} C_{2} R}}{s^{2}+\frac{s}{C_{2} R}+\frac{g_{m}}{C_{1} C_{2} R}}
$$

To obtain the all-pass (AP) function, the input voltage is applied at node $\mathrm{V}_{\mathrm{in} 1}, \mathrm{~V}_{\mathrm{in} 2}$ and $\mathrm{V}_{\mathrm{in} 3}$, however, the inverting amplifier with unit gain is required at not $\mathrm{Vi}_{\mathrm{n} 3}$, then the voltage transfer function is obtained as

$$
\frac{V_{O}}{V_{\text {in }}}=\frac{s^{2}-\frac{s}{C_{2} R}+\frac{g_{m}}{C_{1} C_{2} R}}{s^{2}+\frac{s}{C_{2} R}+\frac{g_{m}}{C_{1} C_{2} R}}
$$

From Eqs. (4) to (8), the natural frequency $\left(\omega_{0}\right)$ and quality factor $(\mathrm{Q})$ can be obtained as

$$
\omega_{0}=\sqrt{\frac{g_{m}}{C_{1} C_{2} R}} \text { and } Q=\sqrt{\frac{g_{m} C_{2} R}{C_{1}}}
$$

If $g_{m}=10 I_{B}$ as written in Eq. (2) the natural frequency and quality factor of the proposed circuit are

$$
\omega_{0}=\sqrt{\frac{10 I_{B}}{C_{1} C_{2} R}} \text { and } Q=\sqrt{\frac{10 I_{B} C_{2} R}{C_{1}}}
$$

It is found from Eq. (10) that the $Q$ and $\omega_{0}$ can be electronically adjusted. In case $\mathrm{C}_{1}=\mathrm{C}_{2}$, it is found that the natural frequency can be adjusted without affecting the quality factor as follows

$$
\omega_{0}=\frac{1}{C} \sqrt{\frac{10 I_{B}}{R}} \text { and } Q=\sqrt{10 I_{B} R}
$$




\section{Simulation results}

The PSpice simulation based on macro-model LT1228 IC was used to prove the performance of the filter. The proposed three-inputs single-output voltage-mode filter shown in Fig. 2 was bias with \pm 5 voltage supplies. It was designed with following active and passive element values: $\mathrm{C}_{1}=\mathrm{C}_{2}=1 \mathrm{nF}, \mathrm{R}=1 \mathrm{k} \Omega$ and $\mathrm{I}_{\mathrm{B}}=100 \mu \mathrm{A}$. With this value of components, the expected value of natural frequency in Eq. (10) is $159.154 \mathrm{k} \mathrm{Hz}$, while the simulation value of natural frequency was $157.398 \mathrm{kHz}$. The deviation was about $1.103 \%$. The error between expected and simulation value of natural frequency suffered from the parasitic elements and tracking error from input to output of LT1228. The gain and phase responses, band-pass (BP), band-stop (BS), high-pass (HP), low-pass (LP) and all-pass (AP) functions are respectively shown in Figs. 3 to 7 . The selection of output responses was done as stated in section 2. This confirms that the proposed filter can provide five standard second order filter responses without changing the circuit topology. The test of transient response of the proposed band-pass response filter was done by applying the input as sinusoidal voltage signal with $80 \mathrm{mVp}$ and $\mathrm{f}=160 \mathrm{kHz}$ into node $V_{\text {in3 } 3}$, while nodes $V_{\text {in1 }}$ and $V_{\text {in2 }}$ were grounded. The measurement of input and output voltage is shown in figure 8 . The tuning of natural frequency with electronic method was tested by adjusting bias current IB as $100 \mu \mathrm{A}$, $200 \mu \mathrm{A}$ and $400 \mu \mathrm{A}$. With these bias current, the simulated natural frequencies were located at $157.398 \mathrm{kHz}, 222.844$ $\mathrm{kHz}$ and $314.775 \mathrm{kHz}$, respectively as shown in Fig. 9. It is found that not only the natural frequency is changed, but the quality factor is also changed according to the expecting in Eq. (10). However, the tuning of natural frequency can be done without affecting the quality factor by simultaneously adjusting value of $\mathrm{C}_{1}$ and $\mathrm{C}_{2}$ as described in Eq. (11). This confirms by the results in Fig. 10 . By varying $C_{1}=C_{2}$ with different values of $0.1 \mathrm{nF}, 1 \mathrm{nF}$ and $10 \mathrm{nF}$, the simulated natural frequencies were 769.13 $\mathrm{kHz}, 78.705 \mathrm{kHz}$ and $7.88 \mathrm{kHz}$. In this case the other component values were set as $\mathrm{I}_{\mathrm{B}}=500 \mu \mathrm{A}$ and $\mathrm{R}=20 \mathrm{k} \Omega$. It is found from Fig. 10 that the natural frequency can be tuned with constant value of quality factor.

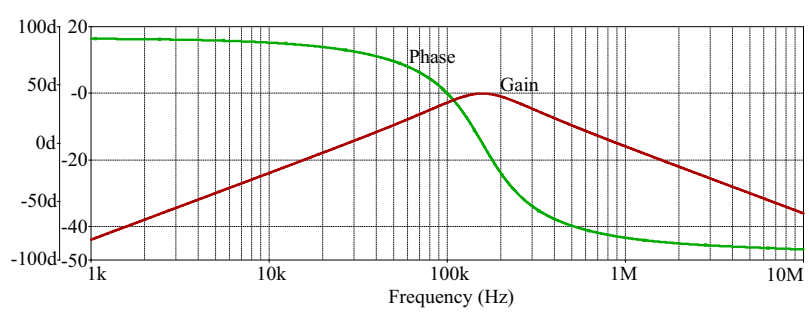

Figure 3. Simulated gain and phase responses for BP filter.

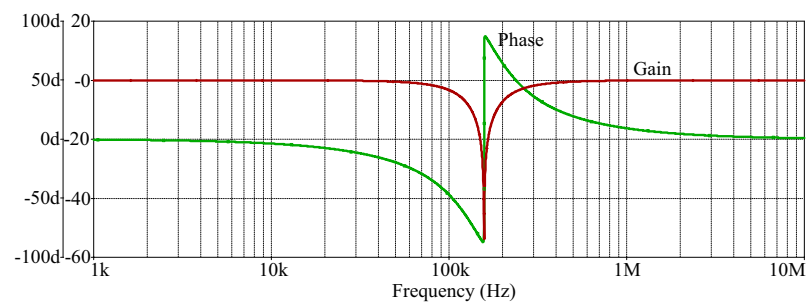

Figure 4. Simulated gain and phase responses for BS filter.

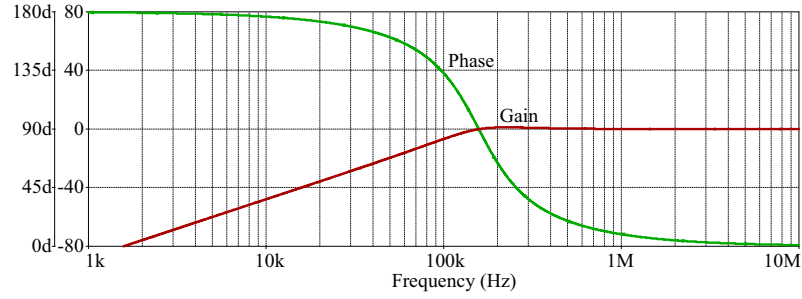

Figure 5. Simulated gain and phase responses for HP filter.

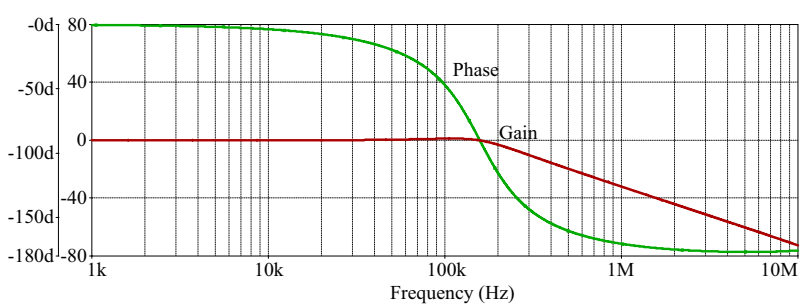

Figure 6. Simulated gain and phase responses for LP filter.

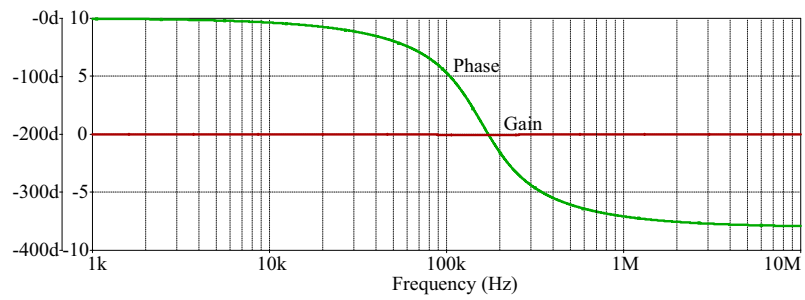

Figure 7. Simulated gain and phase responses for AP filter.

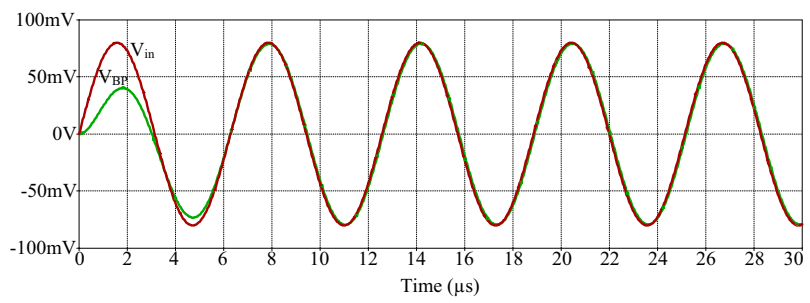

Figure 8. Transient response for BP function.

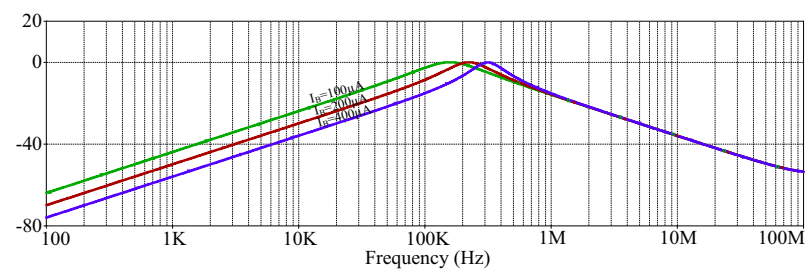

Figure 9. Simulated BP response for three different $I_{B}$ values

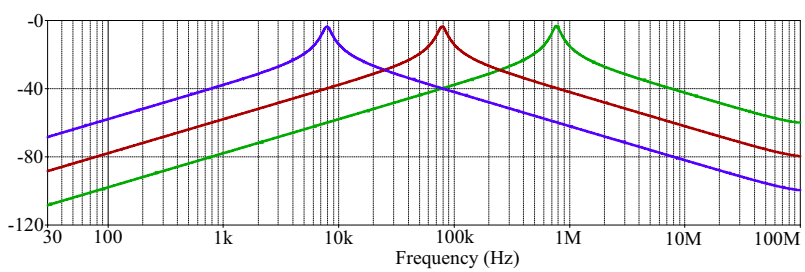

Figure 10. Simulated BP response for three different capacitance values.

\section{Conclusion}

In this paper, the three inputs single output voltage mode filter topology employing the commercially available IC, LT1228 is proposed. The presented filter employs only single LT1228, single resistor and two capacitors. It 
doesn't require passive or active component matching condition to obtain desired filter responses. Also, the selection of filter response can be done without the requirement of double gain amplifier. The natural frequency and quality factor can be tuned electronically. If value of $\mathrm{C}_{1}$ and $\mathrm{C}_{2}$ is simultaneously adjusted, the natural frequency can be tuned without affecting quality factor as analyzed in Eq. (10). The PSpice simulation results using macro-model of LT1228 are agree well with theory anticipation. The proposed filter is considered as simple circuit because it uses only single commercially available IC. However, the voltage buffer is required for cascading and the tune of quality factor cannot be adjusted without affecting the natural frequency.

\section{Acknowledgement}

Research described in this paper was financially supported from Faculty of Industrial Education, King Mongkut's Institute of Technology Ladkrabang (KMITL).

\section{References}

1. A.S. Sedra and K.C. Smith, "Microelectronic circuits," Florida: Holt, Rinehart and Winston 5 (2003)

2. J.W. Horng, "Voltage-mode universal biquadratic filter using two OTAs," Active and Passive Elec Comp. 27, 85-89, (2004).

3. J.W. Horng, "High input impedance voltage-mode universal biquadratic filter using two OTAs and one CCII," Int J Electron. 90, 185-191, (2003).

4. M. Sagbas and M. Koksal, "Voltage mode three input single output multifunction filters employing minimum number of components," Frequenz. 61, 87-93, (2007).

5. C.M. Chang and H.P. Chen, "Single FDCCII-based tunable universal voltage-mode filter," Circuits Syst Signal Process. 24, 221-227, (2005).
6. A. Ranjan and S.K. Paul, "Voltage mode universal biquad using CCCII," Active Passive Electron Compon. 1-5, (2011).

7. W. Tangsrirat, "Novel current-mode and voltagemode universal biquad filters using single CFTA," Indian J Eng Mater Sci. 17, 99-104, (2010).

8. C.M. Chang, H.P. Chen, "Universal capacitorgrounded voltage-mode filter with three inputs and a single output," Int J Electron, 90, 401-406, (2003).

9. S. Kilınc, A.Ü. Keskin and C. Ugur, "Cascadable voltage-mode multifunction biquad employing single OTRA," Frequenz. 61, 84-86, (2007).

10. J.K. Pathak, A.K. Singh and R. Senani, "New voltage mode universal filters using only two CDBAs," ISRN Electron, 1-6, (2013).

11. J.W. Horng, "High-input and low-output impedance voltage-mode universal biquadratic filter using DDCCs," IEEE Trans Circuits Syst II. 54, 649-652, (2007).

12. N.A. Shah and M.A. Malik, "Voltage/current-mode universal filter using FTFN and CFA," Analog Integr Circuits Signal Process. 45, 197-203, (2005).

13. H.P. Chen, "Voltage-mode FDCCII-based universal filters," Int J Electron Commun(AEU). 63, 320-323, (2009).

14. W. Tangsrirat and O. Channumsin. "Voltage-mode multifunctional biquadratic filter using single DVCC and minimum number of passive elements," Indian J PureAppl Phys, 49, 703-707, (2011).

15. W. Ninsraku, D. Biolek, W. Jaikla, S. Sriripongdee and P. Suwanjan, "Electronically controlled high input and low output impedance voltage mode multifunction filter with grounded capacitors," Int J Electron Commun(AEU), 68, 1-8, (2014).

16. LT1228 - $100 \mathrm{MHz}$ Current Feedback Amplifier with DC Gain Control, Linear Technology Corporation, www.linear.com 